\title{
Perspectives in European cooperation in biological oceanography
}

\author{
G. Hempel ${ }^{1,2}$ \\ ${ }^{1}$ Institut für Polarökologie, Universität Kiel, Germany \\ and \\ ${ }^{2}$ Zentrum für Marine Tropenökologie; Universitätsallee GW I/A, D-28359 Bremen, \\ Germany*
}

\section{INTRODUCTION}

Let me first ask: Why cooperation in biological oceanography? The quick answer is: It is "in" and it pays.

International cooperation in science recently became a buzz-word - almost like global change. Funding agencies make it a pre-requisite for giving grants. However, national and international cooperation is not of value in itself. In the past a lot of good marine science has been done without it.

More and more projects depend on the

- pooling of research vessels, buoy systems and remote sensing, for solving scientific problems on a regional and global scale;

- sharing of large equipment, computer centres and tanks, for ambitious experiments;

- pooling of expertise and human resources of various institutes with different scientific profiles, for complex multidisciplinary studies;

- sharing of finances between institutions and national budgets, and drawing financial contributions from international sources, for expensive projects.

Why do we emphasize European cooperation? Europe has a lot to offer. No continent has as much coastline relative to its surface area as Europe. Most seas around Europe are shared by several coastal states. Any comprehensive study of those areas has to involve all riparian countries. Europe houses a vast diversity of marine science institutions with a great variety of scientific traditions.

Europe is undergoing great political changes that have an impact on the marine science scene. The formation of the common economic market means the unrestricted migration of scientific human resources. It also partly means the step from national to international funding. In order to reduce the Darwinian struggle of unlimited competition, the EC sponsors the twinning of strong with weak institutions in joint projects. The MAST programmes of the European Community are based on the concept of joint proposals for projects by two or more institutions in different countries. Each project must

- : Postal address 
fall under one or the other of the broad themes identified by the EC for European cooperation. Participation under the MAST-programme is open to some countries which are as yet outside the EC.

There are many complaints about the bureaucracy in Brussels and about the way in which priority fields are defined. Nevertheless, an increasing number of institutes and scientists are learning to use the system.

The other change refers to Eastern Europe. There, the centralized Soviet system is being replaced by national research structures with new opportunities for international cooperation. But they need the solidarity of their western neighbours.

European cooperation - as strong as it might be - cannot remain in isolation; it is part of the global science community and has to contribute to global programmes.

Most European institutes have traditional links to US institutions and further connections exist to the established overseas centres, for example in Canada, Japan, and in the southern hemisphere. It would be extremely shortsighted not to continue those links, and not to invite overseas participation in European projects right from the planning stage.

For good political, economic and environmental reasons, Europe has to assist Third World countries in developing their expertise and infrastructure in marine and coastal research. What is lacking so far is a common European policy and partnership in marine research and monitoring for Third World countries. Sometimes there is rather too little communication and coordination between the sponsors of various nations, even when operating in the same region. Exchange of experience and standardization of methods would be of great benefit, not only to the Third World institutes, but also to the European scientists working in the field.

I wish to propose joint European projects of training and research planned and carried out under the flag of the EC, but organized by two or three national institutes, drawing on the experience and skilled human resources of various European countries. Such multilateral EC programmes should address basic biological oceanography, but also environmental and resource problems of marine regions of interest to several riparian countries. Along those lines, a lot can be done by multinational research cruises, like the surveys by the research vessels "Dr. Frithjof Nansen" (Norway), "Snellius" (Netherlands) and "Meteor" and "Victor Hensen" (Germany).

How did international cooperation work so far? There is no cooperation without communication. International communication was a forerunner and is still a pre-requisite for successful coordination of research efforts and for cooperation in the strict sense. Anton Dohrn's Stazione Zoologica was the first prominent forum for marine biologists.

After World War II, European researchers met more often in institutions in the US (like Woods Hole) than in European places. The International Helgoland Symposia and the European Marine Biological Symposia created by O. Kinne turned the tide, and called together the European marine biologists and their friends from overseas.

The first step from the international exchange of information, to multi-ship cooperative sea-going programmes, was taken when the International Council for the Exploration of the Sea (ICES) was founded in 1902. Surveys on the distribution of fish stocks in relation to the hydrographical conditions became the backbone of European cooperation in marine science for several decades. The interest in distribution and abundance of fish eggs and larvae resulted in large-scale studies of zooplankton in general, although many 
of them were not well-coordinated at an international level. Multi-ship surveys bloomed in the 1960s and 1970s; they were initiated partly under the umbrella of SCOR and UNorganisations, and partly by ICES and by the Conferences of the Baltic Marine Biologists. Some years later, the need for pollution monitoring became the key to further international cooperation, particularly in the Baltic and North Sea. In most of the multi-ship programmes, practical goals like the management of fish resources and the control of pollution or problems of physical oceanography were the primary forces, and biological oceanographers made good use of those initiatives.

Interest in the productivity of the regions, and its variations in space and time, resulted in joint programmes in the equatorial and coastal upwelling regions and in the Indian Ocean. All those programmes consisted of more or less well-coordinated national cruises, but rarely in proper international working-up and joint publications of the results. In comparison to the storage and retrieval of physical and some chemical data in World Data Centres, international compilation of biological data is far behind.

BIOMASS was the largest international project in biological oceanography. The Biological Investigations of Antarctic Systems and Stocks (1976 to 1991) consisted of acoustic and fishing surveys on krill and fish, as well as of detailed studies on the Antarctic food web, including the top predators like seals and birds. A number of workshops and symposia and the BIOMASS data centre in Cambridge ensured adequate working-up of the results and created and strengthened international contacts. BIOMASS involved scientists from South America, South Africa, the USA and Japan, but the majority of the vessels came from Europe. The programme created a strong community of biological oceanographers interested in the Antarctic ecosystems. Presumably, BIOMASS was more or less the grand finale of the period of multi-ship surveys in biological oceanography.

Basically two types of cooperative studies had been carried out: firstly the rigid schedule by which each participating vessel works along certain predescribed routes in a fixed station grid, and secondly, the loose schedule in which the work-plan of each vessel is rather free, as long as the key measurements and methods are standardized and data exchange is ensured.

Apart from their scientific goals, multi-ship surveys have obvious advantages in terms of science policy. They are relatively easy to "sell" to governmental agencies. They provide a firm backbone to the national cruise programme, keeping the vessels and scientists busy for periods when new scientific ideas are not sparkling. Multi-ship surveys contribute greatly to the standardisation of methods and instruments. They foster international communication, particularly during the planning phase and while the vessels are at sea.

Nevertheless, past experience has shown that the scientific outcome of multi-ship surveys is less important in biological oceanography than, for example, in physical oceanography. Back home the interest of most scientists fades if they have to wait for too long until the last area of research and national group has delivered their data.

In recent years, new types of multi-ship operations have been developed in Europe which take into account some of the difficulties described.

International experiments like FLEX in the North Sea, and the Patch Study in the Baltic were started with a narrow, well-defined scientific goal and a clear experimental design involving several vessels, possibly remote sensing, and moored systems. Firm 
plans for the working-up of the results are already at hand before the experiment starts, and the linkage between the various fields of research is well established.

Although having advocated multi-ship programmes for many years, I myself doubt whether in future they will make the best use of the scientific human resources and research vessels of Europe to answer the burning questions of biological oceanography regarding global change, regional pollution and resource management.

The EPOS Concept. In 1988 a new approach for international cooperation in biological oceanography was launched by the European Science Foundation as part of its network on Polar Science.

For half a year the West German research vessel "Polarstern" was made available for 130 scientists from 11 countries of Western and Central Europe. The vessel carried out three cruise legs to the Weddell Sea. The financial conditions were quite simple. The Alfred Wegener Institute, Bremerhaven, allocated the vessel; the EC contributed to the charter of helicopters; and ESF provided funds for the international planning. The costs for travel and equipment of the participants were borne by their national funding agencies.

The European Polarstern Study, EPOS was directed to investigate the ice biota and the role of sea ice for the pelagic system, as well as for benthos and fishes. In certain respects it was an extension of BIOMASS into the sea ice zone. The expedition covered the seasons from late winter conditions, through the spring and summer blooms in front of the retreating ice until the onset of the new freezing period in autumn. Physical and chemical oceanographers as well as glaciologists provided the necessary background information on the abiotic conditions and participated in interdisciplinary studies on the effects of turbulence and trace elements on primary production.

Planning for EPOS took more than two years. Firstly, an international management group under J. O. Strömberg, Sweden, invited proposals for project elements. The interest shown by the scientific community was staggering. 40 proposals were selected, many potential participants and good suggestions had to be declined. A lot of effort was needed to transform the individual proposals into a coherent programme and form international teams for the various laboratories on board. Each leg was organized by an international advisor and by a leading German scientist. German participation was kept at not more than one third of the total scientific staff.

The expedition was not only directed at scientific questions per se, but was also meant to strengthen links between European marine scientists. EPOS aimed to incorporate many European laboratories, including rather new ones and those which had not participated in Antarctic research. It fostered the exchange between scientists of different categories: non-polar and polar; Arctic and Antarctic; experimental and field; shallow water and oceanic; open water and pack ice. All this resulted in the implantation of new ideas and methods into Antarctic biological oceanography.

A great deal of effort and international funds were spent on the speedy analysis of the results by a number of specialized workshops, followed by a general Symposium. Most of the results were published in multi-author papers, more than 100 altogether.

Some of the international teams established during EPOS have continued during further projects and new cooperations developed over the working-up of the results. In summer 1991 a second EPOS was carried out, this time focussing on the Arctic. Now we had scientists from Poland, the Baltic republics and Russia on board, financed through the 
national funding organizations of the western European participants. Similar to EPOS was the Victor Hensen Centennial Plankton Expedition by R.V. "Meteor", 1989.

Using large national research vessels as common platforms seems to be an effective way of carrying out ambitious scientific projects which require expertise and equipment coming from various quarters. For certain scientific problems it is better to have many groups working together on one vessel, interacting with each other, rather than operating several vessels simultaneously. Using EC funds for chartering one of the many big research vessels of the former Soviet Union might lead to EPOS type activities, provided one national laboratory takes the lead and operates as a scientific and logistic secretariat.

French scientists have proposed to build an European research vessel for the study of the deep-sea floor. Although being primarily meant for core drilling, it would also serve biological purposes. The advantages and disadvantages of such a vessel under the "flag" of the EC are still a matter of debate.

Although biological stations used to be primarily tailored to the study of the physiology, morphology etc., of single marine organisms, they have also played an important role in biological oceanography, by continuous simultaneous observations of biological, physical, and chemical parameters: Scripps Pier and Helgoland Reede stand for high quality long-term data sets on marine variability. Modern approaches to those data holdings are required.

Marine biological stations can work at a principle similar to EPOS. They could provide the platform for international projects combining field and lab work of invited groups of foreign scientists. The $\mathrm{BAH}$ would be ideal for those multinational and multidisciplinary experiments in the North Sea, on the interaction of marine organisms with their environment.

New fields. In early 1990 the Directorate XII of the Commission of the European Communities and the European Science Foundation together established a European Committee on Ocean and Polar Sciences (ECOPS). Its objectives are to develop a longterm European strategy in marine and polar research, and to promote major European projects in ocean and polar studies. In a brochure, "The Ocean and the Poles", and in a memorandum to its governing bodies, the members of ECOPS have outlined certain fields of particular interest and great potential. I will mention only the deep-sea floor and the development of modern technology.

The deep-sea floor and the near-bottom water is a field where European biologists could take the lead. The exploration of the hydrothermal vents and their biota, which are the hot spots - in the true sense - of the ocean bed, has to be supplemented by a programme on the biological variability of the deep-sea floor as a whole.

Until recently, the deep-sea floor, being the largest environment on earth, has been considered the most homogeneous and stable one. Now we have indications of rapid flux of material from surface waters and land to the deepest layers of the ocean. The fast colonization of hydrothermal vents also points to important horizontal transport processes, causing variability in the distribution of organisms on the sea bed. With the increasing threat of dumping and of mining in the deep sea, we should ask about the vulnerability of the deep-sea fauna to human disturbances.

Biological oceanography is lagging far behind physical oceanography in terms of the application of modern technology, both for observing and for modelling the biological processes and distributions in the ocean. There are great opportunities for linking the 
various centres of biological oceanography in Europe with the respective industries, in order to fill this gap. EUROMAR has started this, by the cooperative development of monitoring devices for pollution control. In deep-sea biology we want to go beyond the stage of, for example, sampling the deep midwater layers and the abyssal zone by devices similar to those used by HMS "Challenger" 120 years ago. ECOPS is discussing a network of technology centres, where ocean scientists and engineers would work hand in hand.

In principle, perspectives for European cooperation in the advancement of new methods and instrumentation are very good because of the great potential of European industry and marine science and of recent developments in computer techniques, satellite transmitters, micro-sensors, etc.

Regional projects in global programmes. In addition to the existing physical WOCE (World Ocean Circulation Experiment) and bio-geochemical JGOFS (Joint Global Ocean Flux Study), three major collaborative research projects are presently promoted under the umbrella of ICSU: GLOBEC (Global Ocean Ecosystems Dynamics) is gaining momentum, while LOICZ (Land-Ocean Interactions in the Coastal Zone) and, in particular, GOECS (Global Ocean Euphotic Zone Study) are in the early stages of planning.

Regional projects in European waters will serve the global programmes. Regions which require large-scale European cooperation include the Mediterranean, the Arctic Ocean and the Baltic Sea. As a continuation of EPOS, the Antarctic Sea Ice Zone has also been mentioned. I will deal briefly with the Baltic Sea only.

The political changes in eastern Europe have opened up the entire Baltic Sea. The Baltic Sea is the largest brackish water sea area on earth; it is a more or less enclosed marine ecosystem and provides great opportunities for studies on the effects of natural changes and man-made impacts by fishing and by inputs of nutrients and pollution. Many of the long time-series of environmental data stored in eastern European institutes are only now becoming available. For reasons concerning basic science and environmental control - but also for political reasons - the Baltic Mediterranean may become an important area of scientific cooperation. Second to none, except possibly the North Sea, the Baltic Sea shores house the densest population of marine scientists, particularly biologists.

During a recent tour by the R.V. "Alexander von Humboldt", of the Institute of Baltic Sea Research in Warnemünde, to the marine research institutes of Poland, the three Baltic republics and Russia, I was impressed by the great scientific potential in those countries but also by the economic problems. The risk of a "brain-drain" of highly-skilled scientists is obvious. Any future cooperation in the region will depend on support by the other institutes and countries bordering the Baltic Sea, and from other sources. Much of the support might be through joint projects involving several institutes in eastern, western and northern Europe. The Nordic Council of Scandinavian Countries has launched a major study of the Gulf of Riga, in cooperation with institutes in Latvia and Estonia, making use of a Lithuanian research vessel.

ECOPS is promoting plans for a comprehensive and complex European research programme in the Baltic Sea, and we in Warnemünde have proposed to the EC a series of scientific workshops in order to discuss the scientific elements and technical needs of such a programme - which has to be developed in close cooperation with ICES and the international commissions for fisheries and for pollution in the Baltic. Areas of particular 
interest to biologists are the interaction between eutrophication and fisheries on the structure and productivity of the food web, bio-geochemical fluxes and cycles affected by climatic change, small-scale variability and the transport of organic matter and nutrients across the front between the near shore waters and the open Baltic Sea.

\section{CONCLUSIONS}

European cooperation in biological oceanography is indispensable for geographical, political and financial reasons.

Large-scale regional projects, ocean observation and forescasting systems, the study of the deep-sea bed and the development of modern technology for automated observations require multinational cooperation. Other projects might be carried out on a bi- or trilateral basis.

European cooperation holds great promise because of the high concentration and great variety of research institutions with a large potential of skilled personnel, instruments and many (too many?) research vessels of all sizes. The opening up of the former Eastern bloc provides new opportunities and obligations for European cooperation.

New approaches have been found through the provision of national vessels and installations for international projects. The further integration of European marine science will presumably lead to the establishment of technology centres, and possibly to European research vessels.

The new perspectives of European cooperation are encouraging, provided there will be enough solidarity within Europe during periods of great economic disparity, and provided European marine scientists are aware of the interests of their colleagues in all other parts of the world, rich and poor. 